\title{
Review
}

\section{Plant purple acid phosphatases - genes, structures and biological function}

\author{
Mariusz Olczak ${ }^{\bowtie}$, Bronisława Morawiecka and Wiesław Wątorek \\ Institute of Biochemistry and Molecular Biology, Wroctaw University, Wroctaw, Poland
}

Received: 28 August, 2003; revised: 17 November, 2003; accepted: 27 November, 2003

Key words: metallophosphatases, plant purple acid phosphatases

\begin{abstract}
The properties of plant purple acid phosphatases (PAPs), metallophosphoesterases present in some bacteria, plants and animals are reviewed. All members of this group contain a characteristic set of seven amino-acid residues involved in metal ligation. Animal PAPs contain a binuclear metallic center composed of two irons, whereas in plant PAPs one iron ion is joined by zinc or manganese ion. Among plant PAPs two groups can be distinguished: small PAPs, monomeric proteins with molecular mass around $35 \mathrm{kDa}$, structurally close to mammalian PAPs, and large PAPs, homodimeric proteins with a single polypeptide of about $55 \mathrm{kDa}$. Large plant PAPs exhibit two types of structural organization. One type comprises enzymes with subunits bound by a disulfide bridge formed by cysteines located in the C-terminal region around position 350 . In the second type no cysteines are located in this position and no disulfide bridges are formed between subunits. Differences in structural organisation are reflected in substrate preferences. Recent data reveal in plants the occurrence of metallophosphoesterases structurally different from small or large PAPs but with metal-ligating sequences characteristic for PAPs and expressing pronounced specificity towards phytate or diphosphate nucleosides and inorganic pyrophosphate.
\end{abstract}

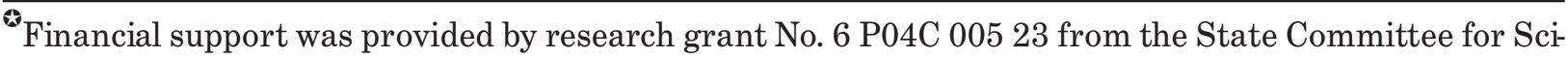
entific Research (KBN, Poland).

${ }^{\otimes}$ Corresponding author: Mariusz Olczak, Institute of Biochemistry and Molecular Biology, Wrocław University, Tamka 2, 51-137 Wrocław, Poland; tel.: (48 71) 375 2710; fax: (48 71) 375 2608; e-mail: olczak@bf.uni.wroc.pl
}

Abbreviations: AP, acid phosphatase; At, Arabidopsis thaliana; kbAP, kidney bean acid phosphatase; PAPs, purple acid phosphatases; PEP, phosphoenolpyruvate; $p$ NPP, para-nitrophenyl phosphate; PPD1-5, nucleotide-diphosphate phosphohydrolase 1-5. 
Acid phosphatases play a key role in phosphate acquisition by plants but, except for a few enzymes performing specific metabolic functions, it is difficult to ascribe a precise role to the majority of them. Research on plant acid phosphatases has a long history yet the available data do not allow to generalize on their structure and function. This is a result of different aspects considered by researchers (Duff et al., 1994). Some of them elaborate on physiology, while other on biochemistry or molecular biology. There is a very limited number of comprehensive reports on the overall aspects of acid phosphatases. The most complete data have been published on the largest group of plant phoshatases known as purple acid phosphatases (PAPs) which occur also in microorganisms and animals (Schenk et al., 2000; Oddie et al., 2000; Vogel et al., 2001). The animal enzymes were purified and characterized from bovine spleen (Campbell \& Zerner, 1973) and pregnant pig uterine fluid (uteroferrin) (Schlosnagle et al., 1974). In humans, they were isolated from the spleen (Yam et al., 1971), bones (Allen et al., 1989), alveolar macrophages (Efstratiadis \& Moss, 1985) and placenta (Ketcham et al., 1989). The level of these enzymes increases in such pathological states as Gaucher disease (Robinson \& Glew, 1980), hairy cell leukemia (Yam et al., 1971), osteoclastoma cells (Hayman et al., 1989) and AIDS (Schindelmeiser et al., 1989).

All PAPs are tartrate-resistant and contain a binuclear metal site. The pink/purple color of their concentrated water solution is the result of a charge-transfer transition between "chromophoric" ferric ion and the tyrosine residue (Vincent \& Averill, 1990). The second "nonchromophoric" metal ion, occupying the binuclear site, is iron in mammalian PAPs, and zinc or manganese in plant enzymes (Vogel et al., 2001).

In mammals, a role of PAPs is ascribed to iron transport (Buhi et al., 1982), bone resorption (Hayman et al., 1996), antigen presenta- tion and some redox reactions (Hayman et al., 2000; Vogel et al., 2001). In plants a role of PAPs remains unknown (Vogel et al., 2001). Two groups of PAPs in plants have been distinguished, first - structurally close to mammalian purple phosphatases, monomeric proteins with a molecular mass around $35 \mathrm{kDa}$, and second - composed of homodimeric proteins with a polypeptide of about $55 \mathrm{kDa}$ (Schenk et al., 2000).

\section{SMALL PLANT PURPLE ACID PHOSPHATASES}

Small plant PAPs are known only from their cDNA sequences (Vogel et al., 2001), except for one example - AtACP5, the enzyme purified to homogeneity from Arabidopsis thaliana (Pozo del et al., 1999). AtACP5 is a secreted, $35 \mathrm{kDa}$ monomeric enzyme. All five PAP metal-binding motifs are present in this protein. Sequence analysis clearly shows that AtCP5 belongs to a group of enzymes closely related to small purple acid phosphatases known from mammalian tissues (type 5 acid phosphatases), e.g. uteroferrin. The enzyme hydrolyzes pNPP, a standard synthetic phosphatase substrate; however, nothing is known about its substrate specificity towards natural phosphoesters. In addition, like mammalian PAPs, AtACP5 exhibits peroxidase activity. It is interesting that AtACP5 production is induced during phosphate starvation, a behavior established for some large, dimeric PAPs (Wasaki et al., 1997; 1999, Miller et al., 2001; Li et al., 2002).

The other known sequences of plant small PAPs were identified in Arabidopsis, sweet potato, soybean and red kidney bean. The putative, mature proteins have approximately 320 amino-acids residues in length and contain all metal binding motifs (Schenk et al., 2000). The existence of these small PAPs was deduced from genomic analysis and confirmed by cloning of cDNA sequences obtained from mRNA template isolated from 
plant tissues. The phylogenetic analysis suggests that small PAPs are closely related to their mammalian and bacterial homologs, in contrast to large plant PAPs, which are more homologous to the enzymes found in fungi and mycobacteria. This may indicate that the division between small and large PAPs groups was a very early event in phosphoesterase evolution.

\section{LARGE PLANT PURPLE ACID PHOSPHATASES}

The most comprehensively characterized enzyme among $55 \mathrm{kDa}$ PAPs was purified from red kidney bean (Beck et al., 1986). The kid- samine and the terminal $N$-acetylglucosamine residues; some have additional, terminal galactosyl residues. The glycan pool is highly heterogeneous, which is typical of secreted plant enzymes. The three-dimensional structure of this protein is known (Sträer et al., 1995) (Fig. 1). The kbAP dimer is heartshaped with dimensions of $40 \times 60 \times 75 \AA$. There are two domains in each of its subunits: a smaller $\mathrm{N}$-terminal domain (about 120 residues) and a larger C-terminal domain (about 210 residues) with [Fe(III)-Zn(II)] metallic center. The subunits are covalently bound by disulfide bridge between cysteines 345 residing in the C-terminal domain. The N-terminal domain is formed by two sandwiched $\beta$ sheets, each composed of three antiparallel $\beta$

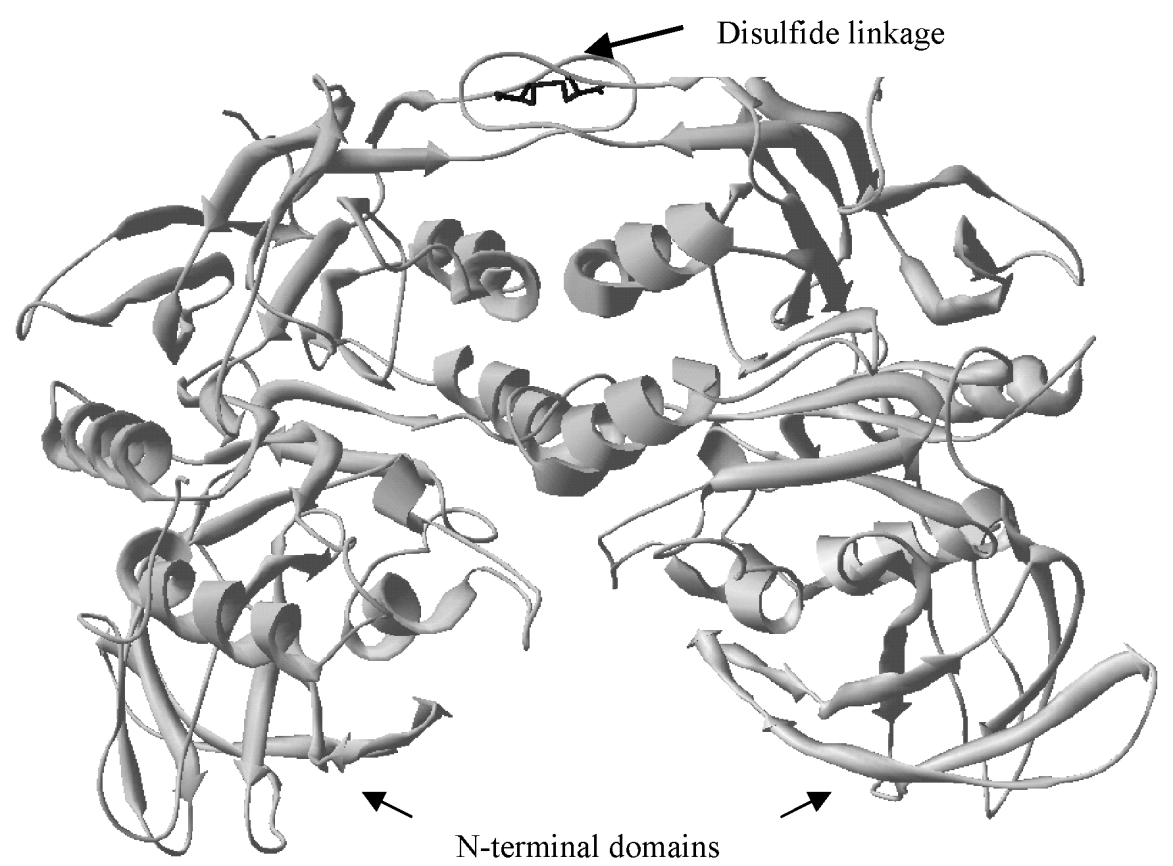

Figure 1. 3D-structure of purple acid phosphatase from red kidney bean (kbAP).

The protein is a homodimer with disulfide linkage between cysteines located at the C-terminal domains. The figure was made with Swiss-PDB Viewer (Guex \& Peitsch, 1997) and rendered in POV-Ray 3.5.

ney bean enzyme (kbAP) contains 432 aminoacid residues per monomer (Klabunde et al., 1994; Stahl et al., 1994) with five N-glycosylation sites, and its sugar moiety comprises of about $11 \%$ of the total molecular mass. All N-glycans have a complex-type xylose-containing structure, most have fucose residues attached to asparagine-bound $\mathrm{N}$-acetylgluco- strands. One edge of this sandwich is shielded by an additional $\beta$ strand. Comparison with known structures of monomeric mammalian PAPs shows that this N-terminal domain is absent in mammalian enzymes (Klabunde et al., 1995). The C-terminal domain contains fragments of $\alpha$ and $\beta$ structures and its core is composed of two sandwiched mixed $\beta$ 
sheets (Fig. 2). In each sheet the metal-coordinating motif $\beta \alpha \beta \alpha \beta$ (characteristic for all metallophosphoesterases) is present. The iron ion is coordinated by Tyr167, by the

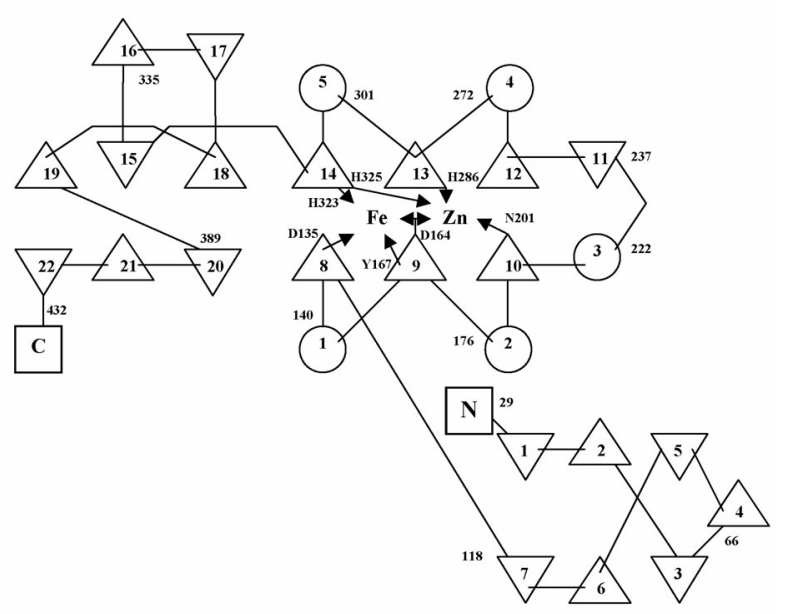

Figure 2. Topology diagram of the kbPAP monomer.

$\beta$-Strands are shown as triangles and $\alpha$-helices as circles. Metal-coordinating amino-acid residues are numbered and depicted with one-letter code. Modified from Klabunde et al., 1996.

$\mathrm{N}^{\varepsilon}$-atom of His325 and by the carboxylate group of Asp135. The $\mathrm{N}^{\varepsilon}$-atom of His286, the $\mathrm{N}^{\delta}$-atom of His323 and amide oxygen of Asn201 coordinate the zinc ion. Both metal ions are bridged by carboxylate group of Asp164.

In PAP metal-assisted catalysis the $\mathrm{S}_{\mathrm{N}}$ 2-type mechanism is proposed (Klabunde et al., 1996) (Fig. 3). The phosphate group of the substrate interacts with the zinc ion by one of the non-estrified oxygen atoms. Other interactions include His202 and His296. This substrate is attacked by Fe(III) bound hydroxide ion. As a result, reorientation of phosphate group occurs and a pentacoordinate intermediate (transition state) bound to two metal ions and two His residues (202 and 296) is formed. Subsequently, His296 is replaced in hydrogen bonding at transition state by His295. After shift, His296 acts as a general acid by protonation of the leaving alcohol group. The catalysis is finished by an attack of a water molecule upon Fe(III) ion, causing an inversion of configuration and release of the phosphate group. The enzyme is relatively non-specific, with some preference for ATP (Beck et al., 1986).

Cloning and comparative modeling of two $55 \mathrm{kDa}$ PAPs from sweet potato showed high sequentional and structural homology to the red kidney bean enzyme (Durmus et al., 1999b). In one sweet potato PAP form a Fe-Mn binuclear metal center was found (Schenk et al., 2001), in the other - a Fe-Zn center, identical with the kbAP metal center (Durmus et al., 1999a).

In the Arabidopsis thaliana genome twenty nine potential PAP genes have been identified (Li et al., 2002). Twenty four putative enzymes contained a typical for PAPs set of seven amino-acids residues involved in metal binding. One putative protein lacked four of these seven residues, four others had metal ligating sequences more similar to those in non-PAPs yeast, bacterial or human metallophosphoesterases with exonuclease or phosphodiesterase activity. This group is evolutionarily distinct from typical large and small PAPs and its biochemical and enzymatic properties are unknown.

Out of twenty four PAPs sequences of A. thaliana, eighteen cDNAs were synthesized using the cytosolic, mature mRNA template. Most of the putative proteins may be classified as large PAPs (molecular mass of approx. $55 \mathrm{kDa}$ per subunit); two of them, AtPAP7 and AtPAP8, belong to the small PAPs family. In addition, the splicing variants of two sequences (AtPAP10 and AtPAP13), truncated at the N-terminus, were found. It was shown that the transcript level of AtPAP10, a large PAPs family member, depended on phosphate concentration in the medium.

Our laboratory has been involved in research on yellow lupin phosphatases for many years. Non-specific acid phosphatase (AP1), with some preference for phos- 
phoenolpyruvate but with low affinity for ATP from yellow lupin seeds belongs to the large PAPs (Olczak et al., 1997). The enzyme is a homodimer, containing $7 \%$ carbohydrate with a known glycan structure. Although the majority of sequenced $\mathrm{N}$-glycans belong to the paucimannosidic type, characteristic for plant vacuolar glycoproteins, $17 \%$ of isolated structures were found to be of the high-mannose type. Most of the complex glycans were both fucosylated and xylosylated; some were either fucosylated or xylosylated (Olczak \& Watorek, 1998). During dormancy $50 \mathrm{kDa}$ subunits of AP1 undergo N-terminal limited which suggests, unlike the red kidney bean enzyme, that they are non-covalently bound. This has recently been confirmed by the analysis of AP1 sequence obtained from its cDNA (Olczak \& Watorek, 2003). Unlike kbAP, the lupin AP1 lacks disulfide bridge-forming cysteine residues around position 340-370. A single cysteine in the sequence is localized in position 119 . In addition, we have recently characterized cDNA for another lupin PAP, AP2, abundant in lupin root (Olczak \& Watorek, 2003). This enzyme is structurally related to the red kidney bean PAP and contains a cysteine residue in position 372 .
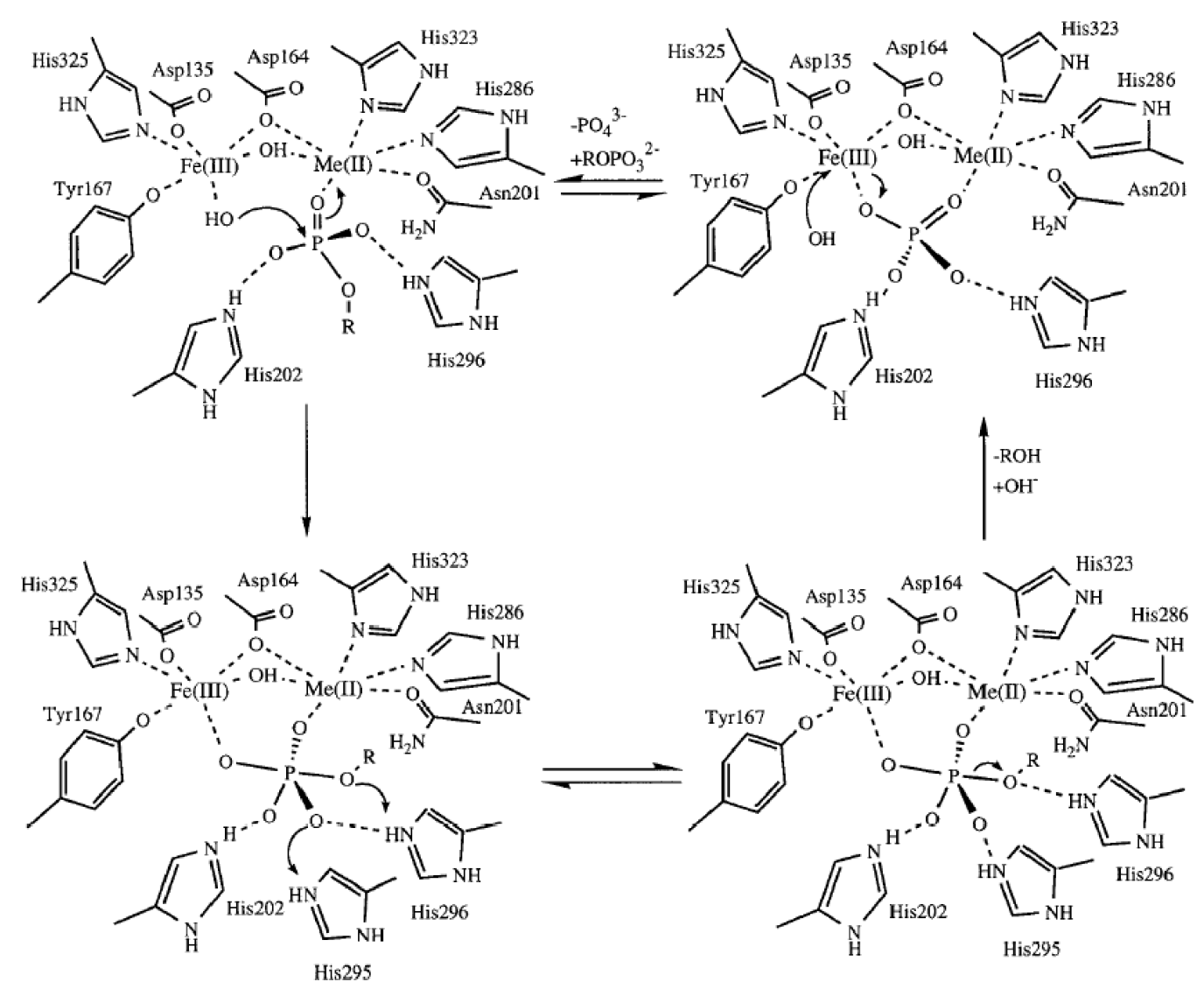

Figure 3. Mechanism of phosphomonoesters hydrolysis by PAP.

The pentacoordinate transition state is presumed to be stabilized by the metal ions, by His202, and by His296. The release of the alcohol component under inversion of the configuration at the phosphorus is presumably promoted by the protonation by His296. The release of the phosphate group requires attack of the water molecule at Fe(III) in order to start another cycle of catalysis. Reprinted from Klabunde et al., 1996, with permission of Elsevier.

proteolytic degradation to $44 \mathrm{kDa}$ (Olczak \& Watorek, 2002). AP1 subunits dissociate during SDS electrophoresis in non-reducing conditions (without disulfide bridge reduction),
We have purified and characterized protein and carbohydrate part of a novel metallophosphatase, diphosphate nucleoside-specific phosphohydrolase (PPD1) (Olczak et al., 
2000; Olczak \& Watorek, 2000). The enzyme contains a full PAP metal-binding motif. Surprisingly, its overall homology to typical, large PAPs is less than 27\%. The molecular mass of the PPD1 subunit is $75 \mathrm{kDa}$, including $4-6 \%$ of N-linked sugar oligomers, i.e., it is significantly larger than a typical, large PAP polypeptide ( $55 \mathrm{kDa}$ ). Although we have found that the monomer of PPD1 could be enzymatically active, the native protein is probably a homopolymer composed of noncovalently bound monomers (unpublished data). PPD1 cleaves pyrophosphate bonds in diphosphonucleosides and phosphodiester bonds in synthetic phosphodiesters with a pH optimum at 6.25. Its physiological role could be related to regulation of diphosphonucleosides or pyrophosphate levels in plant metabolism. The carbohydrate moiety is composed of twenty four different glycan structures of high-mannose, paucimannosidic or complex type. Among complex type glycans, rare structures with Lewis ${ }^{\text {a }}$ epitope were identified. Recent cDNA analysis showed that PPD1 belongs to a new group of plant metallophosphatases (Olczak \& Olczak, 2002). Additional genes and transcripts (PPD2-PPD5) were found in yellow lupin tissues. To date very little is known about the biological function of this group; however, a strong homology to PPD1, the only purified and characterized member of the PPD family, suggests similar enzymatic properties. The sequence analysis of PPD proteins may indicate different localization of the enzymes in the cell. PPD1 is a soluble, secreted protein, PPD2 is predicted to be a membrane enzyme with a high probability of ER localization, and PPD4 is probably located in chloroplasts. For PPD3 and PPD5 only fragments of the sequences are known. Alignment of PPD proteins with small and large plant PAP members shows that PPD enzymes have an additional, non-homologous sequence at the N-terminus, about 150 amino-acids residues in length. The existence of the PPD group (a few putative, similar proteins are present in the
Arabidopsis genome) suggests that the division of the PAPs family between "small" (35 $\mathrm{kDa}$ ), mammalian-like PAPs and non-specific dimeric enzymes with approx. $55 \mathrm{kDa}$ per subunit ("large" PAPs) may be not complete; other purple acid phosphoesterases, like the PPD group, unrelated to either "small" or "large" PAPs have still not been characterized in details.

The most representative plant PAPs sequences are presented in Table 1, comprising only enzymes cloned, sequenced and purified from plant material. Analysis of these se-

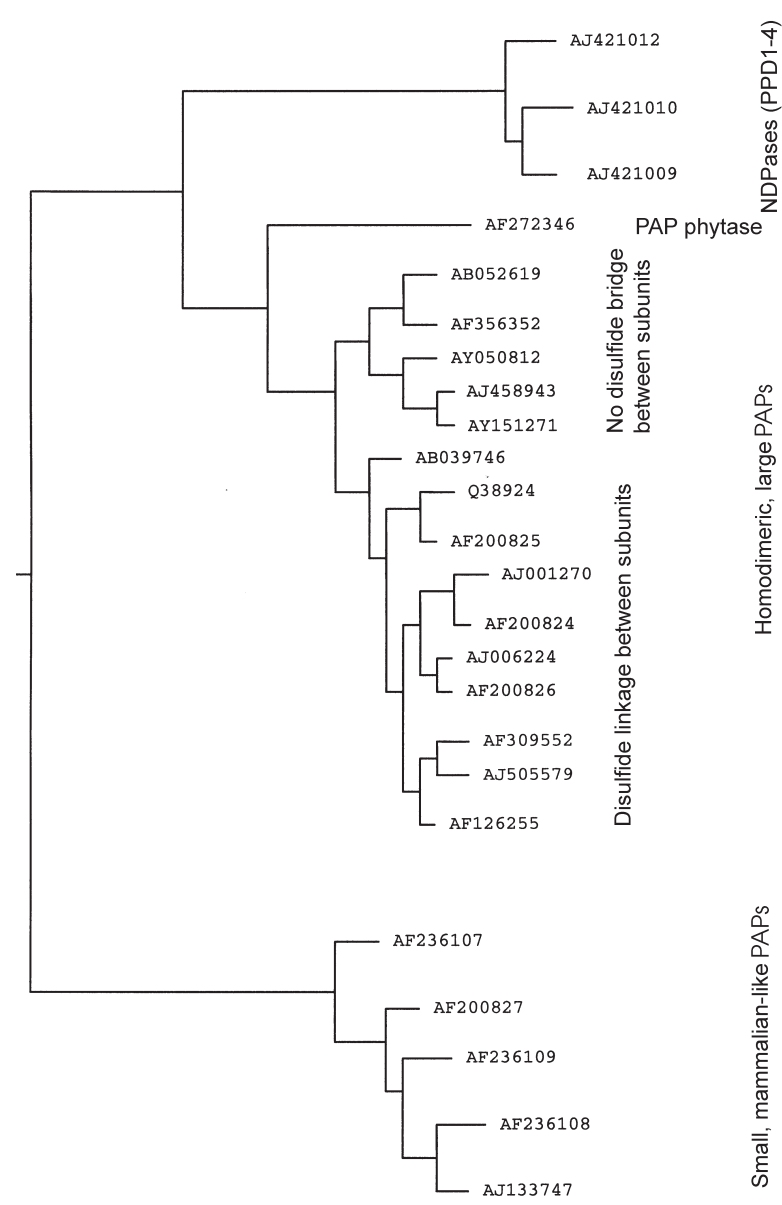

Figure 4. The phylogenetic tree of plant purple acid phosphatases (modified from Olczak \& Watorek, 2003).

The large plant PAPs are divided into two subfamilies differing in subunit linkage.

quences allowed to hypothesize that the "large" PAPs composed of two 50-55 kDa sub- 
units can be divided in two subfamilies differing in the degree of homology and the presence of cysteine residues in positions close to 120 and around 340-370 (Fig. 4). The first subfamily comprises of lupin AP1, phosphatases from rice and onion, and some putative Arabidopsis enzymes. They show 76-68\% homology to AP1. These enzymes do not have cysteine residues around position 340-370 and they are unable to form a disulfide bridge between subunits. All of them have a cysteine residue around position 120 , which does not form a linkage between two subunits. For two members of this subfamily preferences for phosphoenolpyruvate (PEP) are known. The second subfamily is formed by the majority of known plant PAPs, including the red kidney bean enzyme and PAP izoenzymes isolated from batatas and lupin AP2. This subfamily has $59-54 \%$ homology to AP1, contains cysteine 370 (sometimes also cysteine 120) and is able to form a disulfide bridge between the subunits. Although the data concerning substrate specificity of the second large PAP subfamily are very limited, ATP seems to be the preferential substrate.

The phylogenetic analysis showed that the most distinct from mammalian PAPs are the plant high molecular mass lupin PPD enzymes (Olczak \& Olczak, 2002) and phytase purified from soybean (Hegeman \& Grabau, 2001). Database search for proteins homologous to PPD lupin NDPases/phosphodiesterases proved that these enzymes are unique for higher plants, and we found similar putative proteins only in Arabidopsis genome (not published).

\section{POSTTRANSLATIONAL MODIFICATIONS OF PLANT PAPs}

All known purple acid phosphatases are N-glycosylated, which is typical for secreted plant enzymes. Although data concerning detailed structures of attached N-glycans are limited, it seems that in PAPs the prevailing part of the structures consists of paucimannosidic xylosylated and fucosylated N-glycans. Typically, one large (55 kDa) PAP subunit contains $3-5$ potential sites of $\mathrm{N}$-glycosylation and approx. $10 \%$ sugar content (Stahl et al., 1994; Olczak \& Watorek, 1998); however, for proteins secreted outside the cell and induced by low phosphate level, the sugar content may be significantly higher (Miller et al., 2001).

Most known PAPs are secreted, soluble proteins, except for glycosyl-phoshatidylinositol-anchored phosphatase isolated from Spirodela oligorhhiza cell membranes (Morita et al., 1998; Nakazato et al., 1999). This is the only known PAP with experimentally proved membrane localization. Although homologous to other family members, the enzyme from Spirodela oligorrhiza has a neutral $\mathrm{pH}$ optimum, which is unusual for PAPs, generally highly active at $\mathrm{pH} 5-5.5$. The explanation of this phenomenon is not known.

Some enzymes from the PPD group may be also localized in membranes, and one of them, PPD2, is assumed to be an ER-membrane protein, having a non-cleavable transmembrane domain at the N-terminus; however, the enzyme has not been purified from plant tissue nor its localization was proved experimentally (Olczak \& Olczak, 2002).

Recently the sequence of soybean PAP with $82 \%$ homology to secretable lupin AP1 enzyme was published (Liao et al., 2003). The sequence contains unusual for PAP putative mitochondrion targeting transit peptide motif.

As described earlier, the subunits of large plant PAPs form dimeric structures linked by disulfide bond or only by some non-covalent interactions. The analysis of the presence and localization of cysteine around position 120 and/or around position 360, compared to the total number of cysteine residues in known large PAPs sequences strongly suggests that there are no internal disulfide linkages stabilizing the subunit structure (Table 1). It is not known, why large purple acid phosphatases 
form dimeric structures, in contrast to small plant and mammalian PAPs, which are enzymatically active as monomeric proteins.

\section{FUNCTION OF PLANT PAPs}

Purple plant acid metallophosphatases are abundant in plant tissues. Most PAPs are unspecific, hydrolyzing a broad spectrum of phosphate esters, including ATP, PEP, sugar ters. The same function can be assigned to PAPs localized in vacuoles, taking part in utilization of some vacuolar metabolites. The role of phosphate acquisition from glycolytic PEP during low-phosphate stress was proposed by Duff et al. (1994); however, this mechanism requires the transport of PEP into, and pyruvate out of the vacuoles, which has not been discovered in plant tissues.

Some PAPs play an auxiliary role in the utilization of phytate, one of the most important

Table 1. Selected properties of plant purple acid phosphatases

\begin{tabular}{|c|c|c|c|c|c|c|c|c|c|}
\hline \multirow{6}{*}{$\begin{array}{l}\text { Source of PAP } \\
\text { and EMBL } \\
\text { accesion number } \\
\text { Lupinus luteus AJ458943 } \\
\text { Arabidopsis thaliana AY050812 } \\
\text { Oryza sativa AF356352 } \\
\text { Allium cepa AB052619 } \\
\text { Glycine max AY151271 }\end{array}$} & \multirow{6}{*}{$\begin{array}{c}\begin{array}{c}\text { Cysteine } \\
\text { around } \\
\text { pos. } 120^{\mathrm{a}}\end{array} \\
\text { GYVHHC } \\
\text { GFIHHC } \\
\text { GYIHHC } \\
\text { GYIHHC } \\
\text { GYIHHC }\end{array}$} & \multirow{6}{*}{$\begin{array}{l}\begin{array}{l}\text { Cysteine } \\
\text { around } \\
\text { pos. } 360^{\text {a }}\end{array} \\
\text { SGHRFPI } \\
\text { SGDRYPV } \\
\text { SGNRYPV } \\
\text { SGNRYPI } \\
\text { GGNRYPL }\end{array}$} & \multirow{2}{*}{$\begin{array}{c}\begin{array}{l}\text { Number of } \\
\text { cysteines }\end{array} \\
1\end{array}$} & \multirow{2}{*}{$\begin{array}{l}\text { Length } \\
\text { of the subunit } \\
\\
477\end{array}$} & \multicolumn{4}{|c|}{ PAP conserved motifs } & \multirow{2}{*}{$\begin{array}{l}\begin{array}{l}\text { Substrate } \\
\text { preference }\end{array} \\
\text { PEP }^{c, d}\end{array}$} \\
\hline & & & & & GDLG & & VLME & \multirow{5}{*}{$\begin{array}{l}\text { GHVH } \\
\text { GHVH } \\
\text { GHVH } \\
\text { GHVH } \\
\text { GHVH }\end{array}$} & \\
\hline & & & 1 & 475 & & & VLMH & & \\
\hline & & & 2 & 476 & & & & & \multirow{3}{*}{ PEP } \\
\hline & & & 2 & 481 & & & VLMH & & \\
\hline & & & 1 & 512 & & & VLMH & & \\
\hline Spirodela oligorrhiza AB039746 & GYIHHC & DGKCTPT & 2 & 455 & & & VLMH & & \multirow{10}{*}{$\operatorname{ATP}^{\mathrm{f}}$} \\
\hline Ipomoea batatas AJ006224 & GYIHHC & NGECTPV & 2 & 465 & & & VLME & & \\
\hline Ipomoea batatas AF200826 & GYIHHC & NGKCTPV & 2 & 465 & & & VLMH & & \\
\hline Ipomoea batatas AF200825 & AFIHHC & NAKCTPV & 2 & 472 & & & VLVH & & \\
\hline Glycine max AF200824 & GEIHHT & NGLCAPV & 1 & 464 & & & VLMH & & \\
\hline Arabidopsis thaliana Q38924 & GYIHнC & NGLCEPI & 4 & 469 & 西 & $\mathrm{NHE}$ & VLVH & & \\
\hline Lupinus Iuteus AJ505579 & GEIHHT & NGICTPV & 1 & 463 & & & VLMH & & \\
\hline Phaesolvus vulgaris AJ001270 & GEIHHT & NGLCTPV & 1 & 459 & & & VLMH & & \\
\hline Anchusa officinalis AF126255 & GFIHH $\mathbf{C}$ & NGICTPV & 2 & 470 & & $\mathrm{HHE}$ & VLME & & \\
\hline Lupinus albus AF309552 & GFIHHT & NGICTPV & 1 & 460 & GDLG & $\mathrm{NHE}$ & VLMH & & \\
\hline Glycine max AF272346 & GIIHHV & GPVYITV & 11 & 547 & GDLG & GDVTY & VTWL & & \multirow{4}{*}{$\frac{\text { Phytate }}{\text { NDP } \text { PP }_{i}{ }^{i}}$} \\
\hline Lupinus Iuteus AJ421009 & GYIHTS & EKHNYKG & 11 & 615 & GDMG & GDLGY & FLAH & & \\
\hline Lupinus Iuteus AJ421010 & GEIHTS & EKHHYKG & 11 & 612 & $\mathrm{GD}$ & & FLAH & & \\
\hline Lupinus luteus AJ421012 & GFIHTS & EKTHYSG & 9 & 597 & GDMG & GDLPY GNHE & VSAH & GHVH & \\
\hline Arabidopsis thaliana AJ133747 & NA & SGAGSKA & 2 & 338 & GDWG & $\mathrm{ANHD}$ & VVGH & & \\
\hline Arabidopsis thaliana AF200827 & NA & SGGGSKA & 4 & 314 & GDWG & & VIGH & & \\
\hline Ipomoea batatas AF236107 & NA & SGGGSKA & 2 & 311 & & & VVGH & & \\
\hline Glycine max AF236108 & NA & SGGGFKA & 3 & 332 & & GDNFY GNHD & VVGH & & \\
\hline Phaesolvus vulgaris AF236109 & NA & SGAGSKA & 5 & 331 & GDWG & GDNEY GNHD & VIGH & & \\
\hline
\end{tabular}

${ }^{\mathrm{a}}$ The positions of cysteines in non-mature protein containing a signal sequence; ${ }^{\mathrm{b}}$ Without cysteines in signal peptide; 'Olczak \& Watorek, 2003; ${ }^{\mathrm{d}}$ Olczak et al., 1997; ${ }^{\mathrm{e}}$ Shinano et al., 2001; ${ }^{\mathrm{f}}$ Beck et al., 1986; ${ }^{\mathrm{g}}$ Miller et al., 2001; ${ }^{\mathrm{h}}$ Hegeman \& Grabau, 2001; ${ }^{\mathrm{i}}$ Olczak et al., 2000; 2001; NA, not applicable.

phosphates, mononucleotides and inorganic pyrophosphate. Their function is unknown; although some biological functions have been proposed. First, regulation of some PAPs transcripts by phosphate level in the medium and soil strongly suggests an important role for these enzymes in phosphate acquisition. Phosphate-regulated PAPs can be secreted outside the root cells to the extracellular environment, hydrolyzing various phosphate es- phosphate storage compounds in plants. During germination, the PAP-phytase isolated from soybean cotyledones (Hegeman \& Grabau, 2001) efficiently hydrolyses phytate. Homologous phytase sequences also have been found in Arabidopsis genome (Li et al., 2002). However, the majority of plant phytate hydrolyzing activity is probably performed by enzymes unrelated to the PAP family. For example, the cDNA synthesized on maize mRNA template encodes 38 
$\mathrm{kDa}$ protein, which is phylogenetically distinct from PAPs (Mougenest et al., 1997). The maize enzyme is related to phytate-hydrolyzing histidine acid phosphatases found in fungi (Mitchell et al., 1997).

NDPase/diphosphoesterase, PPD1, isolated from yellow lupin may be involved in regulation of diphosphonucleotide or pyrophosphate level in plant cells (Olczak et al., 2000).

The peroxidase activity of mammalian and plant small PAPs (Pozo del et al., 1999) may suggest that these enzymes are involved in removal of reactive oxygen compounds in stressed or senescent plant organs. In mammalian PAPs, the phosphatase and oxygen radical-generating activities are functionally independent as shown by site-directed mutagenesis of a murine recombinant purple acid phosphatase (Kaija et al., 2002).

The two metal ions per each subunit of a PAP molecule and the abundance of these enzymes in plant tissues may suggest that the proteins take part in iron, zinc and molybdenum transport and storage.

\section{CONCLUDING REMARKS}

For more than 30 years many papers on plant purple acid phosphates have been published; however, data describing this enzyme family are still fragmentary and many questions remain open: What is the function of non-catalytic N-terminal domains in large PAPs? What is the biological importance of the dimeric structure of large PAPs, as contrasted with small PAPs, which are functional as monomers? Why do some PAPs contain two iron ions in a subunit when others have iron and zinc or manganese as a second ion? Is the PAPs peroxidase activity biologically important for plant tissues?

The combined application of genetic, biochemical and immunological methods is necessary to elucidate these problems. Antibodies to a particular PAP enzyme could be a powerful tool in investigating the enzyme in vivo, but it is not an easy task because of the presence of numerous highly homologous PAPs in the same plant tissue. The overexpression of PAPs known only from its DNA coding sequence, not purified from plant material, would be useful in PAPs investigation, for example in substrate specificity analyses, crystallography studies and site-directed mutagenesis. Recently, recombinant fully active red kidney bean PAP has been overexpressed in insect baculovirus system (Vogel et al., 2002).

\section{R E F E R E N C E S}

Allen SH, Nuttleman PR, Ketcham CM, Roberts RM. (1989) Purification and characterization of human bone tartrate-resistant acid phosphatase. J Bone Miner Res.; 4: 47-55.

Beck JL, McConaghie LA, Summors AC, Arnold WN, de Jersey J, Zerner B. (1986) Properties of a purple acid phosphatase from red kidney bean: a zinc-iron metalloenzyme. Biochim Biophys Acta.; 869: 61-8.

Buhi WC, Ducsay CA, Bazer FW, Roberts RM. (1982) Iron transfer between the purple phosphatase uteroferrin and transferrin and its possible role in iron metabolism of the fetal pig. J Biol Chem.; 257: 1712-3.

Campbell HD, Zerner B. (1973) A low-molecular-weight acid phosphatase which contains iron. Biochem Biophys Res Commun.; 54: 1498-03.

Duff SMG, Sarath G, Plaxton WC. (1994) The role of acid phosphatases in plant phosphorus metabolism. Physiol Plant.; 90: 791-800.

Durmus A, Eicken C, Sift BK, Kratel A, Kappl R, Hütermann J, Krebs B. (1999a) The active site of purple acid phosphatase from sweet potatoes (Ipomoea batatas). Metal content and spectroscopic characterization. Eur J Biochem.; 260: 709-16.

Durmus A, Eicken C, Spener F, Krebs B. (1999b) Cloning and comparative modeling of two purple acid phosphatase isozymes 
from sweet potatoes (Ipomoea batatas). Biochim Biophys Acta; 1434: 202-9.

Efstratiadis T, Moss DW. (1985) Tartrate-resistant acid phosphatase in human alveolar macrophages. Enzyme.; 34: 140-3.

Guex N, Peitsch MC. (1997) SWISS-MODEL and the Swiss-PDBViewer: an environment for comparative protein modeling. Electrophoresis.; 18: 2714-3.

Hayman AR, Warburton MJ, Pringle JA, Coles B, Chambers TJ. (1989) Purification and characterization of a tartrate-resistant acid phosphatase from human osteoclastomas. Biochem J.; 261: 601-9.

Hayman AR, Jones SJ, Boyde A, Foster D, Colledge WH, Carlton MB, Evans MJ, Cox TM. (1996) Mice lacking tartrate-resistant acid phosphatase (Acp 5) have disrupted endochondral ossification and mild osteopetrosis. Development.; 122: 3151-2.

Hayman AR, Bune AJ, Bradley JR, Rashbass J, Cox TM. (2000) Osteoclastic tartrate-resistant acid phosphatase (Acp 5): its localization to dendritic cells and diverse murine tissues. J Histochem Cytochem.; 48: 219-28.

Hegeman CE, Grabau EA. (2001) A novel phytase with sequence similarity to purple acid phosphatases is expressed in cotyledons of germinating soybean seedlings. Plant Physiol.; 126: 1598-108.

Kaija H, Alatalo SL, Haleen JM, Lindqvist YL, Schneider G, Väänäen HK, Vihko P. (2002) Phosphatase and oxygen radical-generating activities of mammalian purple acid phosphatase are functionally independent. Biochem Biophys Res Commun.; 292: 128-2.

Ketcham CM, Roberts RM, Simmen RC, Nick HS. (1989) Molecular cloning of the type 5, iron-containing, tartrate-resistant acid phosphatase from human placenta. $J$ Biol Chem.; 264: 557-3.

Klabunde T, Stahl B, Suerbaum H, Hahner S, Karas M, Hillenkamp F, Krebs B, Witzel H. (1994) The amino acid sequence of the red kidney bean Fe(III)-Zn(II) purple acid phosphatase. Determination of the amino sequence by a combination of matrix-assisted laser desorption/ionization mass spectrometry and automated Edman sequencing. Eur J Biochem.; 226: 369-75.

Klabunde T, Sträer N, Krebs B, Witzel H. (1995) Structural relationship between the mammalian Fe(III)-Fe(II) and Fe(III)-Zn(II) plant purple acid phosphatases. FEBS Lett.; 376: $56-60$.

Klabunde T, Sträer N, Fröhlich R, Witzel H, Krebs B. (1996) Mechanism of Fe(III)-Zn(II) purple acid phosphatase based on crystal structures. J Mol Biol.; 259: 737-48.

Li D, Zhu H, Liu K, Leggewie G, Udvardi M, Wang D. (2002) Purple acid phosphatases of Arabidopsis thaliana. Comparative analysis and differential regulation by phosphate deprivation. J Biol Chem.; 277: 27772-81.

Liao H, Wong FL, Phang TH, Cheung MY, Li WY, Shao G, Yan X, Lam HM. (2003) GmPAP3, a novel purple acid phosphatase-like gene in soybean induced by $\mathrm{NaCl}$ stress but not phosphorus deficiency. Gene.; 318: 103-11.

Miller SS, Liu J, Allan DL, Menzhuber CJ, Fedorova M, Vance CP. (2001) Molecular control of acid phosphatase secretion into the rizosphere of proteoid roots from phosphorus-stressed white lupin. Plant Physiol.; 127: $594-106$.

Mitchell DB, Vogel K, Weimann BJ, val Loon APBM. (1997) The phytase subfamily of histidine acid phosphatases: isolation of genes for two novel phytases from fungi Aspergillus terreus and Myceliophthora thermophila. Microbiology.; 143: 245-52.

Morita N, Nakazato H, Okuyama H, Kim Y, Thomson GA. (1998) Evidence for a glycosylinositolphospholipid - anchored alkaline phosphatase in a aquatic plant Spirodela oligorrhiza. Biochim Biophys Acta.; 1290: $53-62$.

Mougenest S, Martinez I, Lescure A-M. (1997) Cloning and characterization of a cDNA encoding a maize seedling phytase. Biochem J.; 322: $511-7$.

Nakazato H, Okamoto T, Nishikoori M, Washio K, Morita N, Haraguchi K, Thomson GA, 
Okuyama H. (1998) The

glycosylphosphatidylinisitol-anchored phosphatase from Spirodela oligorrhiza is a purple acid phosphatase. Plant Physiol.; 118: 1015-20.

Oddie GW, Schenk G, Angel NZ, Walsh N, Guddat LW, De Jersey J, Cassady AI, Hamilton SE, Hume DA. (2000) Structure, function and regulation of tartrate-resistant acid phosphatase. Bone.; 27: 575-84.

Olczak M, Watorek W. (1998) Oligosaccharide and polypeptide homology of lupin (Lupinus luteus) acid phosphatase subunits. Arch Biochem Biophys.; 360: 85-92.

Olczak M, Watorek W. (2000) Structural analysis of N-glycans from yellow lupin (Lupinus luteus) seed diphosphonucleotide phosphatase/phosphodiesterase. Biochim Biophys Acta.; 1523: 236-45.

Olczak M, Olczak T. (2002) Diphosphonucleotide phosphatase/phosphodiesterase from yellow lupin (Lupinus luteus) belongs to a novel group of specific metallophosphatases. FEBS Lett.; 519: 159-63.

Olczak M, Watorek W. (2002) Processing of $\mathrm{N}$-glycans of two yellow lupin phosphohydrolases during seed maturation and dormancy. Phytochemistry.; 61: 645-55.

Olczak M, Watorek W. (2003) Two subfamilies of plant purple acid phosphatases. Physiol Plant.; 118: 491-98.

Olczak M, Watorek W, Morawiecka B. (1997) Purification and characterization of acid phosphatase from yellow lupin (Lupinus luteus) seeds. Biochim Biophys Acta.; 1341: 14-25.

Olczak M, Kobialka M, Watorek W. (2000) Characterization of diphosphonucleotide phosphatase/phosphodiesterase from yellow lupin (Lupinus luteus) seeds. Biochim Biophys Acta.; 1478: 239-47.

Pozo del JC, Allona I, Rubio V, Leyva A, Pena de la A, Aragoncillo C, Paz-Ares J. (1999) A type 5 acid phosphatase gene from Arabidopsis thaliana is induced by phosphate starvation and by some other types of phos- phate mobilising/oxidative stress conditions. Plant J.; 19: 579-89.

Robinson DB, Glew RH. (1980) A tartrate-resistant acid phosphatase from Gaucher spleen. Purification and properties. J Biol Chem.; 255: $5864-70$.

Schenk G, Guddat LW, Ge Y, Carrington LE, Hume DA, Hamilton S, de Jersey J. (2000) Identification of mammalian-like purple acid phosphatases in a wide range of plants. Gene.; 250: 117-25.

Schenk G, Korsinczky MLJ, Hume DA, Hamilton S, DeJersey J. (2000) Purple acid phosphatases from bacteria: similarities to mammalian and plant enzymes. Gene.; 255: 419-24.

Schenk G, Boutchard CL, Carrington LE, Noble Cj, Moubaraki B, Murray KS, de Jersey J, Hanson GR, Hamilton S. (2001) A purple acid phosphatase from sweet potato contains an antiferromagnetically coupled binuclear Fe-Mn center. J Biol Chem.; 276:19084-8.

Schindelmeiser J, Gullotta F, Munstermann D. (1989) Purple acid phosphatase of human brain macrophages in AIDS encephalopathy. Pathol Res Pract.; 185: 184-6.

Schlosnagle DC, Bazer FW, Tsibris JC, Roberts RM. (1974) An iron-containing phosphatase induced by progesterone in the uterine fluids of pigs. J Biol Chem.; 249: 7574-9.

Stahl B, Klabunde T, Witzel H, Krebs B, Steup M, Karas M, Hillenkamp F. (1994) The oligosaccharides of the Fe(III)-Zn(II) purple acid phosphatase of the red kidney bean. Determination of the structure by a combination of matrix-assisted laser desorption/ionization mass spectroscopy and selective enzymic degradation. Eur J Biochem.; 220: 321-30.

Sträter N, Klabunde T, Tucker P, Witzel H, Krebs B. (1995) Crystal structure of a purple acid phosphatase containing a dinuclear Fe(III)-Zn(II) active site. Science.; 268: 1489-92.

Vincent JB, Averill BA. (1990) An enzyme with a double identity: purple acid phosphatase and tartrate-resistant acid phosphatase. FASEB J.; 4: 3009-14. 
Vogel A, Spener F, Krebs B. (2001) Purple acid phosphatase. In Handbook of metalloproteins. Messerschmidt A, Huber R, Wieghardt K, Poulos T, eds, vol 2, pp 752-66. J. Wiley\&Sons, Chichester.

Vogel A, Borchers T, Marcus T, Meyer HE, Krebs B, Spener F. (2002) Heterologous expression and characterization of recombinant purple acid phosphatase from red kidney bean. Arch Biochem Biophys.; 401: 164-72.

Wasaki J, Ando M, Ozawa K, Omura M, Osaki M, Ito H, Matsui H, Tadano T. (1997) Prop- erties of secretory acid phosphatase from lupin roots under phosphorus-deficient conditions. Soil Sci Plant Nutr.; 43: 981-6.

Wasaki J, Omura M, Osaki M, Ito H, Matsui H, Shinano T, Tadano T. (1999) Structure of a cDNA for an acid phosphatase from phosphate-deficient lupin (Lupinus albus L.) roots. Soil Sci Plant Nutr.; 45: 439-49.

Yam LT, Li CY, Lam KW. (1971) Tartrate-resistant acid phosphatase isoenzyme in the reticulum cells of leukemic reticuloendotheliosis. $N$ Engl J Med.; 284: 357-60. 